\title{
Mortality among oral contraceptive users: 20 year follow up of women in a cohort study
}

\author{
M P Vessey, L Villard-Mackintosh, K McPherson, D Yeates
}

\author{
Abstract \\ Objective-To see whether the use of oral contra- \\ ceptives influences mortality.
}

Design-Non-randomised cohort study of 17032 women followed up on an annual basis for an average of nearly 16 years.

Setting-17 Family planning clinics in England and Scotland.

Subjects-Women recruited during 1968-74. At the time of recruitment each woman was aged 25-39, married, a white British subject, willing to participate, and either a current user of oral contraceptives or a current user of a diaphragm or intrauterine device (without previous exposure to the pill).

Main outcome measures-Overall mortality and cause specific mortality.

Results-238 Deaths occurred during the follow up period. The main analyses concerned women entering the study while using either oral contraceptives or a diaphragm or intrauterine device. The overall relative risk of death in the oral contraceptive users was $0.9(95 \%$ confidence interval 0.7 to $1 \cdot 2)$. Though the numbers of deaths were small in most individual disease categories, the trends observed were generally consistent with findings in other reports. Thus the relative risk of death in the oral contraceptive users was $4.9(95 \%$ confidence interval 0.7 to 230 ) for cancer of the cervix, $3.3(95 \%$ confidence interval 0.9 to 17.9 ) for ischaemic heart disease, and $0.4(95 \%$ confidence interval 0.1 to 1.2$)$ for ovarian cancer. There was a linear trend in the death rates from cervical cancer and ovarian cancer (in opposite directions) with total duration of oral contraceptive use. Death rates from breast cancer (relative risk $0.9 ; 95 \%$ confidence interval 0.5 to 1.4 ) and suicide and probable suicide (relative risk 1.1; $95 \%$ confidence interval 0.3 to 3.6 ) were much the same in the two contraceptive groups. In 1981 the relative risk of death in oral contraceptive users from circulatory diseases as a group was reported to be $\mathbf{4 \cdot 2}$ (95\% confidence interval 2.3 to $7 \cdot 7$ ) in the Royal College of General Practitioners oral contraception study. The corresponding relative risk in this study was only $1.5(95 \%$ confidence interval 0.7 to 3.0$)$.

Conclusions-These findings contain no significant evidence of any overall effect of oral contraceptive use on mortality. None the less, only small numbers of deaths occurred during the study period and a significant adverse (or beneficial) overall effect might emerge in the future. Interestingly, the mortality from circulatory disease associated with oral contraceptive use was substantially less than that found in the Royal College of General Practitioners study.

\section{Introduction}

In 1968 a cohort study was started in collaboration with the Family Planning Association to assess the beneficial and harmful effects of different methods of contraception. A report on mortality among the women taking part was published in 1981 when 89 deaths had occurred.' This paper describes the findings on mortality up to the end of 1987 (marking the 20th anniversary of the start of the study), by which time 238 women had died. Though this number is small, it is none the less closely comparable to the number of deaths (249) reported in the other British cohort study of the long term effects of oral contraceptives (the Royal College of General Practitioners study $^{2}$ ), and follow up in our study has been more complete.

Use of oral contraceptives is believed to influence the risk of several diseases which may have a fatal outcome. Thus there is strong evidence that they increase the risk of hepatocellular adenoma ${ }^{3}$ and carcinoma ${ }^{+}$and of various cardiovascular disorders ${ }^{5}$ (myocardial infarction, stroke, and venous thromboembolism). There is less convincing evidence that they increase the risk of carcinoma of the cervix, ${ }^{6}$ though there is suspicion about a possible adverse effect on the risk of breast cancer ${ }^{7}$ and malignant melanoma ${ }^{8}$ and on the likelihood of suicide. ${ }^{9}$ On the benefit side there is little doubt that oral contraceptives protect against ovarian ${ }^{10}$ and endometrial cancer ${ }^{11}$ and their high level of effectiveness almost eliminates the risk of unwanted pregnancy.

In view of the range of effects of oral contraceptives we considered that the overall level of mortality in the groups compared in the analysis would be of the greatest interest. This was reinforced by the limited power of the study; we estimated that with a test of significance at the 5\% level the study would have a $90 \%$ chance of detecting an overall relative risk (oral contraceptive users to non-users, or vice versa) of 1.4 or more. None the less, we also decided to examine mortality from the individual diseases referred to above, though recognising the lack of power of the study for detecting even major effects after subdivision of the data.

\section{Subjects and methods}

The methods used in the Oxford-Family Planning Association study have been detailed elsewhere. ${ }^{12}$ In brief, 17032 women were recruited at 17 large family planning clinics in England and Scotland during 1968-74. At the time of recruitment each woman had to be $(a)$ aged 25-39, $(b)$ married, $(c)$ a white British subject, $(d)$ willing to participate, and $(e)$ either a current user of oral contraceptives with at least five months of use or a current user of a diaphragm or an intrauterine device with at least five months of use without previous exposure to the pill. During follow up each woman is questioned at return visits to the clinic by a doctor or nurse and certain items of information recorded, including details of pregnancies and their outcome, changes in contraceptive practices 
and reasons for the changes, and reasons for referral to hospital. Women who stop attending the clinic are sent a postal questionnaire and, if this is not returned, are interviewed on the telephone or at a home visit. Each hospital admission is followed up with the consultant concerned and a copy of the discharge summary obtained. The work in each clinic is coordinated by a part time research assistant and follow up has been maintained with an annual loss rate (because of withdrawal of cooperation or loss of contact, excluding emigration) of only about $0 \cdot 3 \%$. The records of all participants in the study were tagged in the National Health Service central registers in Southport and Edinburgh at the time of recruitment, so that deaths are notified automatically.

When women reach the age of 45 they are divided into three groups: those who have never used the pill; those with eight or more years' use of the pill; and the remainder. Only women in the first two groups are subsequently followed up in the way described. The women in the third group are followed up only by means of the National Health Service central registers.

The analyses which follow are based on the computation of woman years of observation in the contraceptive groups compared. Death rates are standardised by an indirect method. ${ }^{12}$ Variables taken into account in the standardisation are age (five year groups 25-29, 30-34, etc), parity (none, one or two, or three or more births), social class at entry (registrar general's classification; I + II, III, IV + V), and smoking habit at entry (never smoked, ex-smoker, and current smoker of 1-4, $5-14,15-24$, or 25 or more cigarettes daily).

\section{Results}

By the end of $1987,735(4 \cdot 3 \%)$ of the women in the study had emigrated; information about the date of embarkation was obtained either from the women themselves or from the National Health Service central registers. In addition, 989 women $(5 \cdot 8 \%)$ had withdrawn their cooperation and $3404(20.0 \%)$ were no longer being followed up in detail, having attained the age of 45 . This report, however, is concerned only with deaths (as ascertained by means of the central registers), so it was possible to include all 17032 women in the analysis save for those emigrating (who were omitted from the date of their embarkation). These 17032 women had been followed up for a total of 271268 person years, an average of nearly 16 years per woman. A total of 238 of the women had died.

The main analysis was conducted according to the method of contraception which a woman was using at the time of recruitment. In addition, women using a

TABLE I Death rates per 100000 woman years by entry cohort and by cause. Except where stated otherwise figures in parentheses are numbers of deaths

\begin{tabular}{|c|c|c|c|}
\hline \multirow[b]{2}{*}{ Cause (ICD) code 8 th revision), } & \multicolumn{2}{|c|}{ Entry cohort } & \multirow[b]{2}{*}{$\begin{array}{l}\text { Ratio of rates } \\
\text { (95\% confidence } \\
\text { interval) }\end{array}$} \\
\hline & $\begin{array}{c}\text { Oral contraceptive } \\
\text { users }\end{array}$ & $\begin{array}{l}\text { Diaphragm/ } \\
\text { intrauterine } \\
\text { device users }\end{array}$ & \\
\hline Neoplasms $(140-239$ & $49 \cdot 9(70)$ & $61 \cdot 1(80)$ & $0.8(0.6$ to $1 \cdot 1)$ \\
\hline Malignant melanoma $(172)$ & $0.7(1)$ & $0 \cdot 7(1)$ & $1 \cdot 0(0$ to 68$)$ \\
\hline Breast cancer 174 & $23 \cdot 1(31)$ & $27 \cdot 1(37)$ & $0.9(0.5$ to 1.4$)$ \\
\hline Cervical cancer 180 & $4 \cdot 4 \cdot 7)$ & $0 \cdot 9(1)$ & $4 \cdot 9(0.7$ to 230$)$ \\
\hline Corpus cancer ( 182 & $0(0)$ & $1+4(2)$ & 0 \\
\hline Ovarian cancer (183) & $3 \cdot 6 \cdot 5$ & $9 \cdot 1(12)$ & $0.4(0.1$ to 1.2$)$ \\
\hline Other tumours & $17 \cdot 7(26)$ & $21 \cdot 6(27)$ & $0.8(0.5$ to 1.5$)$ \\
\hline Diseases of the circulatory system $(390-458)$ & $16 \cdot 0(25)$ & $10 \cdot 4(12)$ & $1.5(0.7103 .0)$ \\
\hline Ischaemic heart disease $(410-414)$ & $9 \cdot 2(15)$ & $2 \cdot 8(3)$ & $3.3(0.9$ to 17.9$)$ \\
\hline Cerebrovascular disease $(430-438)$ & $4 \cdot 2(7)$ & $2 \cdot 9(3)$ & $1.4(0.3$ to $8 \cdot 5)$ \\
\hline Other circulatory diseases & $2 \cdot 4(3)$ & $4 \cdot 1(6)$ & $0.6(0 \cdot 1$ to $2 \cdot 7)$ \\
\hline Accidents and violence $(800-999)$ & $8 \cdot 414$ & $7 \cdot 6(8)$ & $1 \cdot 1(0 \cdot 4$ to $3 \cdot 0)$ \\
\hline Suicide and probable suicide & $6 \cdot 1+10$ & $5 \cdot 6(6)$ & $1 \cdot 1(0.3$ to 3.6$)$ \\
\hline Other accidents and violence & $2 \cdot 3+4$ & $2 \cdot 0 \cdot 2$ & $1 \cdot 1: 0 \cdot 2$ to $12 \cdot 4$ \\
\hline All other causes & $9 \cdot 9$ & $11 \cdot 7(14)$ & $0.8(0.4$ to 1.9$)$ \\
\hline All causes & $84 \cdot 3(124)$ & $90 \cdot 9(114)$ & $0.9(0.7$ to 1.2$)$ \\
\hline
\end{tabular}

Rates are standardised for age, parity, social class, and smoking habits ( see text). Rates are individually standardised and may not therefore total exactly within categories. diaphragm or intrauterine device at entry were combined to simplify analysis. Of the 152597 woman years of observation accumulated by the 9653 women in the oral contraceptive entry group, 51524 woman years $(33 \cdot 8 \%)$ were spent actually using the pill and the remainder spent using other methods (diaphragm 4002 woman years $(2 \cdot 6 \%)$, intrauterine device 9576 woman years $(6 \cdot 3 \%)$, condom 18696 woman years $(12 \cdot 3 \%)$, sterilisation 46353 woman years $(30 \cdot 4 \%)$ ) or no method of contraception. Of the 118671 woman years of observation accumulated by the 7379 women in the diaphragm and intrauterine device entry group, only 5555 woman years $(4 \cdot 7 \%)$ were spent using oral contraceptives. This indicated that those women who entered the study as non-users of the pill tended strongly to remain non-users; accordingly, analysis by entry cohort seemed valid.

Because the study began in 1968 most of the exposure to oral contraceptives was to brands which are no longer in widespread use. Thus of the 51524 woman years of pill use in the oral contraceptive entry cohort, 1050 woman years $(2 \cdot 0 \%)$ represented use of pills containing $>50 \mu \mathrm{g}$ oestrogen, 37302 woman years $(72 \cdot 4 \%)$ use of pills containing $50 \mu \mathrm{g}$ oestrogen, and 8433 woman years $(16.4 \%)$ use of pills containing $<50 \mu \mathrm{g}$ oestrogen; progestogen only pills accounted for the remaining 4739 woman years $(9 \cdot 2 \%)$. Corresponding figures for the 5555 woman years of pill use in the diaphragm and intrauterine device entry cohort were $60(1 \cdot 1 \%), 2778(50 \cdot 0 \%), 1727(31 \cdot 1 \%)$, and 990 $(17 \cdot 8 \%)$ woman years respectively.

The main results of the mortality analysis are shown in table I, which, in addition to providing the overall figures, concentrates on causes of death of special interest in relation to the use of oral cont ceptives. The overall death rates in the two cohorts were closely similar (relative risk $0.9 ; 95 \%$ confidence interval 0.7 to $1 \cdot 2$ ) and, indeed, none of the individual differences noted reached statistical significance. Nevertheless, some interesting associations deserve comment despite the wide confidence intervals attached to many of the relative risk estimates. Firstly, seven of the eight deaths from carcinoma of the cervix occurred in the pill entry cohort (relative risk $4.9 ; 95 \%$ confidence interval 0.7 to 230 ) and both deaths from uterine corpus cancer occurred in the diaphragm and intrauterine device entry cohort. Secondly, the death rate from ovarian cancer (all tumours were of the epithelial type) in the pill entry cohort was less than half that in the diaphragm and intrauterine device entry cohort (relative risk $0 \cdot 4 ; 95 \%$ confidence interval $0 \cdot 1$ to $1 \cdot 2$ ). Thirdly, mortality from ischaemic heart disease was over three times higher in the pill entry cohort than in the diaphragm and intrauterine device entry cohort (relative risk $3.3 ; 95 \%$ confidence interval 0.9 to 17.9 ) and there was a much smaller difference in the same direction for cerebrovascular disease.

There were also some entirely negative findings (table I): there were only two deaths from malignant melanoma (one in each entry cohort); there was no suggestion of a difference in mortality from cancer of the breast between the cohorts (relative risk $0.9 ; 95 \%$ confidence interval 0.5 to 1.4 ); suicide and probable suicide occurred with equal frequency in the two cohorts. Only one woman in the study died of a primary liver tumour (angiosarcoma not shown in table); she had never used oral contraceptives. No woman had died of venous thrombosis or embolism, of pelvic inflammatory disease, or of any other known complication associated with using an intrauterine device or as a direct consequence of pregnancy or labour.

To provide an indication about the level of mortality in our study as a whole as compared with that in the general population we applied the age specific female 
death rates for England and Wales for the year 1980 (as a representative year) to the woman years at risk. On that basis a total of 417 deaths would have been expected in the study whereas only 238 were observed (standardised mortality ratio 57). Other standardised mortality ratios were: all neoplasms 75 , malignant melanoma 102, breast cancer 94 , cervical cancer 50 , corpus cancer 98 , ovarian cancer 106, all diseases of the circulatory system 42 , ischaemic heart disease 53 , cerebrovascular disease 33 , and accidents and violence 44.

Further analyses were undertaken on the deaths from cancer of the breast, cervix, and ovary and on the deaths from ischaemic heart disease and cerebrovascular disease. In these analyses the study data were considered as a whole rather than as from two separate entry cohorts. Taking the deaths from cancer first, we focused our attention on the effect of total duration of pill use, partly because recent patterns of use would have been distorted by the course of the fatal illness and partly because detailed analyses of incident cases have been reported elsewhere. ${ }^{13-15}$ Table II gives the findings. There was no evidence of any relation between death from breast cancer and duration of pill use whereas the deaths from cancer of the cervix were strongly concentrated in the group with the longest duration of use and the deaths from ovarian cancer were strongly concentrated in non-users of the pill and in those using the pill for short durations only.

TABLE II - Deaths from cancer of the breast and reproductive organs by total duration of oral contraceptive use. Data are rates per 100000 woman years of observation (numbers of deaths in parentheses)

Total duration of oral contraceptive use (months)

\begin{tabular}{lcccc} 
& & & & \\
\cline { 2 - 5 } Disease & Never & $\leqslant 47$ & $48-95$ & $\geqslant 96$ \\
\hline Breast cancer & $28 \cdot 5(32)$ & $18 \cdot 3(8)$ & $30 \cdot 2(17)$ & $18 \cdot 6(11)$ \\
Cervical cancer & $1 \cdot 1(1)$ & $0(0)$ & $3 \cdot 1(2)$ & $7 \cdot 4(5)$ \\
Ovarian cancer & $9 \cdot 2(10)$ & $12 \cdot 1(5)$ & $1 \cdot 8(1)$ & $1 \cdot 5(1)$
\end{tabular}

Rates are standardised for age, parity, social class, and smoking habits (sec text)

$\chi_{i 1}^{2}$ for trend: breast cancer (four groups) $=0.76(p=0.38)$; cervical cance three groups $)=4.78(\mathrm{p}=0.03)$; ovarian cancer (three groups $)=3.78(\mathrm{p}=$ $0.05)$.

Of the 18 women dying of ischaemic heart disease, all but two came to necropsy; acute myocardial infarction was considered definitely to be the cause of death in 15 and was presumed to be the cause of death in three. All but one of the women were smokers at entry to the study, the amount smoked varying from seven to 35 cigarettes (mean 18) daily. Fifteen of the women had used oral contraceptives at some time, but only two were using them at the time of death. Among the 13 women who stopped oral contraceptives before death, six did so because of a rise in blood pressure, one because of the onset of intermittent claudication, and one because of "an abnormal blood test." Apart from cigarette smoking and use of oral contraceptives all but five of the 18 women had other features in their history relevant to their fatal illness (some women had more than one). Thus six had a history of severe chest pain, angina pectoris, or myocardial infarction (two of these died shortly after coronary artery bypass grafting), five had a history of toxaemia of pregnancy (one of these suffered a fatal cardiac arrest during pregnancy), three were known hypertensives, one had diabetes mellitus, one had mitral valve disease (she died after mitral valve replacement), and one had severe atheromatous disease of the iliac and femoral arteries.

Of the 10 women dying of cerebrovascular disease, one (a cigarette smoker at entry who was also using the pill at the time of death) died of a massive thrombosis of the left internal carotid artery (proved angiographically) and one (a non-smoker and non-user of the pill) died suddenly of a massive intracerebral haemorrhage (proved at necropsy). The remaining eight died of subarachnoid haemorrhage proved surgically, by computed tomography, or at necropsy in seven. Five of these women were cigarette smokers at entry and seven had used oral contraceptives, though none was doing so at the time of death. Only one woman had stopped taking the pill because of raised blood pressure and only two were known hypertensives.

The relation between death from ischaemic heart disease and subarachnoid haemorrhage and total duration of oral contraceptive use is shown in table III.

TABLE III-Death from ischaemic heart disease and subarachnoid haemorrhage by total duration of oral contraceptive use. Data are rates per 100000 woman years of observation (numbers of deaths in parentheses)

\begin{tabular}{lcccc}
\hline & \multicolumn{3}{c}{ Total duration of oral contraceptive use (months) } \\
\cline { 2 - 5 } Disease & Never & $\leqslant 47$ & $48-95$ & $\geqslant 96$ \\
\hline $\begin{array}{l}\text { Ischaemic heart disease } \\
\begin{array}{l}\text { Subarachnoid } \\
\text { haemorrhage }\end{array}\end{array}$ & $3 \cdot 3(3)$ & $12 \cdot 9(5)$ & $\underbrace{7 \cdot 7(5)}$ & $6 \cdot 4(5)$ \\
\hline
\end{tabular}

Rates are standardised for age, parity, social class, and smoking habits (see Rates

$\chi^{2}$ for heterogeneity: ischaemic heart disease (four groups $)=3.62(p=0.31)$; subarachnoid haemorrhage $($ three goups $)=5.92(p=0.05)$.

The numbers were too small for conclusions to be drawn, but there was a suggestion that both types of fatal event were commoner after shorter durations of pill use than after longer durations. Table IV relates the deaths from ischaemic heart disease and subarachnoid haemorrhage to recency of oral contraceptive use. The excess mortality from ischaemic heart disease which was apparent in the women most recently using oral contraceptives was also apparent in those stopping the pill six or more years before the fatal event. The association between subarachnoid haemorrhage and oral contraceptives was apparent only in those stopping the preparations at least one year before death.

TABLE IV-Death from ischaemic heart disease and subarachnoid haemorrhage by recency of oral contraceptive use. Data are rates per 100000 woman years of observation (numbers of deaths in parentheses)

\begin{tabular}{|c|c|c|c|c|}
\hline \multirow[b]{2}{*}{ Disease } & \multicolumn{4}{|c|}{ Recency of oral contraceptive use (months) } \\
\hline & Never & $\leqslant 12$ & 13-71 & $\geqslant 72$ \\
\hline Ischaemic heart disease & $3 \cdot 3(3)$ & $6 \cdot 7(3)$ & $9 \cdot 0(5)$ & $8 \cdot 6(7)$ \\
\hline Subarachnoid haemorrhage & $1 \cdot 2(1)$ & $0(0)$ & $3 \cdot 1(2)$ & $7 \cdot 9(5)$ \\
\hline
\end{tabular}

Finally, we tried to see if death from ischaemic heart disease or subarachnoid haemorrhage was related to the use of any particular brand of oral contraceptive. Probably not surprisingly given the small numbers of deaths available for analysis, no clear findings emerged. Nevertheless, only one of the women dying of ischaemic heart disease and one dying of subarachnoid haemorrhage had ever used modern pills containing less than $50 \mu \mathrm{g}$ oestrogen.

\section{Discussion}

Taken overall, the results of this analysis of all 17032 women recruited to the Oxford-Family Planning Association study give no cause for concern, in that the death rate was slightly lower in the oral contraceptive entry cohort than in the diaphragm and intrauterine device entry cohort (relative risk $0 \cdot 9 ; 95 \%$ confidence interval 0.7 to $1 \cdot 2$ ). None the less, the numbers of 
deaths which had occurred were small and an adverse (or beneficial) overall effect of oral contraceptive use might emerge in the future. Furthermore, the general level of mortality in the Oxford-Family Planning Association study is and always has been low (overall standardised mortality ratio in 1977,50 ; in 1981,53 ; in this report 57). ${ }^{16}$ Hence the findings in our selected population must be extrapolated with caution to the population at large. We have discussed elsewhere the likely reasons why mortality is generally low in our study ${ }^{16}$; they include the favourable social class distribution, the low level of cigarette smoking, and the orientation of the women towards healthy behaviour as evidenced, for example, by their attendance at family planning clinics.

The data on individual causes of death, though for the most part based on small numbers, yielded some interesting findings. Only two deaths ccurred from malignant melanoma (one in each entry ohort) . . dd the only death from a liver tumour (an angiosarcoma) occurred in a non-user of the pill. Plainly, these results can do little more than serve as a reminder that death from these causes is rare in women of childbearing age. No evidence was found of any association between use of oral contraceptives and death from breast cancer, which accords well with the results of our analysis of incident cases of this disease. ${ }^{13}$ Hardly any of the women in the Oxford-Family Planning Association study, however, used oral contraceptives before the age of 20; it is use at a young age that is most under suspicion as possibly influencing the risk of breast cancer. ${ }^{17}$ The tendency for fatal cancer of the cervix to occur in long term users of the pill was also a feature of our analysis of incident cases of this disease. ${ }^{14}$ There is considerable evidence from other studies as well that prolonged use of the pill has an adverse effect on the risk of cervical cancer, but it is difficult to be sure that inadequately controlled confounding - especially by sexual behavioural factors-is not responsible for the association. ${ }^{6}$ That both deaths from corpus cancer occurred in the diaphragm and intrauterine device entry cohort is consistent with the known protective effect of the combined pill against this disease." Likewise, the lower rate of fatal ovarian cancer in the pill entry cohort was expected ${ }^{10}$ and consistent with our earlier analysis of incident cases. ${ }^{15}$ No protective effect of less than four years of pill use was apparent against death from ovarian cancer, but the risk seemed to be greatly reduced thereafter.

None of the women died of venous thromboembolism; this is not surprising in view of the rarity of death from this cause in women of childbearing age. Our earlier analysis of non-fatal venous thromboembolic disease disclosed a clear relation with the use of oral contraceptives. ${ }^{18}$

The data on fatal cerebrovascular diseases are too few to interpret, but the trend was consistent with a possible association with pill use, as found both in a previous analysis of our own incident cases ${ }^{19}$ and in other studies. ${ }^{5}$ The data on fatal ischaemic heart disease are a little more extensive and of considerable interest. Firstly, only one death occurred in a nonsmoker; this further underlines the dangers of cigarette smoking and is also consistent with the impression that oral contraceptives increase the risk of ischaemic heart disease only in those who smoke. ${ }^{20}$ Secondly, the increased risk of fatal ischaemic heart disease was not concentrated only in current and recent users of oral contraceptives. Instead, there seemed to be an increased risk of a similar magnitude even in those who had discontinued oral contraceptives six or more years before the fatal event. We emphasise that this finding is based on small numbers of events and its interpretation is further complicated by the medical histories of the women who died. None the less, it relates to a highly topical issue about which there remains some doubt in published work. Thus Slone et al found evidence in a large case-control study that the risk of myocardial infarction persisted in women stopping oral contraceptives after long term use. ${ }^{21}$ Such an effect, however, was not found in the nurses' health study"2 or in the Royal College of General Practitioners oral contraception study. "2 Further work is needed on this important question.

Though our findings are clearly consistent with there being an adverse effect of oral contraceptive use on mortality from diseases of the circulatory system, they are certainly less worrying than the results of the Royal College of General Practitioners oral contraception study.' In an analysis of that study, reported in 1981 and based on 249 deaths (similar to the number in this series), women who had used the pill had a $40 \%$ higher overall mortality than women who had never taken the pill (relative risk $1.4 ; 95 \%$ confidence interval $1 \cdot 1$ to $1 \cdot 8$ ). Furthermore, virtually all the excess mortality was attributable to diseases of the circulatory system, for which the relative risk was $4 \cdot 2(95 \%$ confidence interval $2 \cdot 3$ to $7 \cdot 7)$. The corresponding relative risk in our study was only $1.5(95 \%$ confidence interval 0.7 to $3 \cdot 0$ ). Several workers have questioned the high relative risk for diseases of the circulatory system found in the Royal College of General Practitioners study and have pointed out that it is inconsistent with vital statistical trends. ${ }^{23+4}$ Our results are consistent with the view that the risks of cardiovascular death may have been overestimated in the Royal College of General Practitioners study. The Oxford-Family Planning Association study, however, is concerned with a particularly healthy group of women with a low overall mortality who may therefore be less susceptible than the general population to the cardiovascular adverse effects of the pill.

Finally, data have been published suggesting that women using oral contraceptives might be at a higher risk of suicide than non-users." An earlier study of ours, based on the Oxford-Family Planning Association data and considering attempted suicide as well as successful suicide, could not confirm the suggestion. ${ }^{25}$ Our latest findings are consistent with our earlier results.

We are continuing to monitor mortality in the Oxford-Family Planning Association study. In due course our findings should shed further light on the long term and delayed effects, both beneficial and harmful, of oral contraceptive use.

We thank Mrs P Brown, Mrs C Brice, Mrs D Collinge, our research assistants, and the staff of the participating clinics for their continued loyal support. We also thank the Medical Research Council, the Imperial Cancer Research Fund, and the Knott Family Trust for financial help.

\footnotetext{
1 Vessey MP, McPherson K, Yeates 1). Mortality in oral contraceptive users Lancet $1981 ; \mathrm{i}: 549-50$.

Royal College of General Practitioners Oral Contraception Study Group. Further analyses of mortality in oral contraceptive users. Lancet 1981: 541-6.

3 Rooks JB, Ory HW, Ishak KG, et al. Epidemiology of hepatocellular adenoma. The role of oral contraceptive use. 7 AMA 1979;242:644-8.

4 Forman D, Vincent TJ, Doll R. Cancer of the liver and the use of oral contraceptives. Br Med f 1986:292:1357-61.

5 Vessey MP. Female hormones and vascular disease-an epidemiological overview. British fournal of Family Planning 1980;6(suppl): 1-12.

6 Vessey $M$, (irice D. Carcinoma of the cervix and oral contraceptives epidemiological studies. Biomed Pharmacother 1989;43:157-60.

7 Schlesselman JJ. Oral contraceptives in relation to cancer of the breast and reproductive tract-an epidemiological overview. British fournal of Family Planning 1989;15:23-33.

8 Beral V, Evans S, Shaw H, Milton (i. Oral contraceptive use and malignant melanoma in Australia. Br f Cancer 1984:50:681-5.

9 Kay CR. The Royal College of General Practitioners oral contraception study some recent observations. Clin Obstet (ivnecol 1984;11:759-86.

10 Cancer and Steroid Hormone Study (iroup. The reduction in risk of ovarian cancer associated with oral contraceptive use. $N$ kngl f Med 1987;316:650-5. Cancer and Steroid Hormone Study Group. Combination oral contraceptive use and the risk of endometrial cancer. 7 AMA 1987;257:796-800.

12 Vessev M, Doll R, Peto R, Johnson B, Wiggins P. A long-term follow-up study
} 
women using different methods of contraception - an interim report. f Biosoc Sci 1976;8:373-427.

13 Vessey MP, McPherson K, Villard-Mackintosh L, Yeates D. Oral contracep tives and breast cancer: latest findings in a large cohort study. $\mathrm{Br} F$ Cancer $1989 \cdot 59 \cdot 613-7$

14 Vessey MP, Lawless M, McPherson K, Yeates D. Neoplasia of the cervix uteri and contraception: a possible adverse effect of the pill. Lancet 1983;ii:930-4.

15 Vessev M, Metcalfe A, Wells C, McPherson K, Westhoff C, Yeates D). Ovarian neoplasms, functional ovarian cysts, and oral contraceptives. Br Med 1987:294:1518-20.

16 Vessey MP, McPherson K, Johnson B. Mortality among women participating in the Oxford-Family Planning Association contraceptive study. Lance 1977;ii:731-3.

17 McPherson K, Vessey MP, Neil A, Doll R, Jones I., Roberts M. Early oral contraceptive use and breast cancer: results of another case-control study. $B r \mathcal{F}$ Cancer 1987;56:653-60.

18 Vessey M, Mant D, Smith A, Yeates D. Oral contraceptives and venous thromboembolism: findings in a large prospective studv. $\mathrm{Br} \mathrm{Med}$ $1986 ; 292: 526$
19 Vessey MP, Lawless $M$, Yeates D. Oral contraceptives and stroke: findings in a large prospective study. Br Med f 1984;289:530-1.

20 Croft P. Hannaford PC. Risk factors for acute myocardial infarction in women: evidence from the Royal College of General Practitioners' oral contraception evidence from the Royal College of

21 Slon D, Shapiro S, Kaufua DW, Rosenberg L, Miettinen OS, Stolley PD. Risk of myocardial infarction in relation to current and discontinued use of Risk of myocardial infarction in relation to current

22 Stampfer MJ, Willet WC, Colditz GA, Speizer FE, Hennekens $\mathrm{CH}$. A prospective study of past use of oral contraceptive agents and risk of prospective study of past use of oral contraceptive a

23 Goldzieher JW. Oral contraceptive hazards-1981. Fertil Steril 1981;35:275-6. 24 Wiseman RA, MacRae KD. Oral contraceptives and the decline in mortality from circulatory disease. Fertil Steril 1981;35:277-83.

25 Vessey MP, McPherson K, Lawless M, Yeates D. Oral contraception and serious psychiatric illness: absence of an association. $\mathrm{Br} \mathcal{F}$ Psychiatr 1985; 146:45-9.

(Accepted II October 1989)

\title{
Snoring in children: association with respiratory symptoms and passive smoking
}

\author{
Giuseppe M Corbo, Fulvia Fuciarelli, Antonio Foresi, Fernando De Benedetto
}

\begin{abstract}
Objective-To investigate the relation between snoring and various respiratory symptoms and passive parental smoking.

Design-Data were collected by questionnaire.

Setting-Primary schools in Guardiagrele and

Francavilla in the Abruzzi region in central Italy.

Subjects-1615 Children aged 6-13 years were categorised according to whether they snored often; occasionally apart from with colds; only with colds; or never.

Results -118 Children were habitual snorers and 137 were reported to snore apart from when they had colds. Never snorers $(n=822)$ were significantly older than children in other categories. Snoring was significantly associated with rhinitis, production of cough and sputum, previous tonsillectomy, and passive parental smoking. Of the habitual snorers, 82 were exposed to passive smoking. The prevalence of habitual snoring increased significantly with the number of cigarettes smoked by parents (from 5.5\% in moderate smoking households to $8.8 \%$ in heavy smoking households).

Conclusions-Snoring is quite common in children. The dose-effect relation of smoking and snoring shown in this study adds weight to a further adverse effect of parental smoking on children's health.
\end{abstract}

\section{Divisione di Pneumologia} Pediatrica, Centro

Auxologico Italiano, 28044

Verbania (NO), Italy

Giuseppe M Corbo, MD

senior registrar

Antonio Forest, MD, registrar

Istituto di Clinica Medica, Servizio di Fisiopatologia Respiratoria, 66110 Chieti, Italy

Fulvia Fuciarelli, MD attending physician Fernando De Benedetto, $\mathrm{MD}$, senior registrar

Correspondence and requests for reprints to: Dr Corbo.

Br Med f 1989;299:1491-4

\section{Introduction}

Although snoring is often regarded as trivial, it has been associated with hypertension, ${ }^{1-5}$ heart disease, ${ }^{2-6}$ and stroke, ${ }^{6}$ and it is considered to be the first step towards the development of the sleep apnoea syndrome..$^{7.9}$ Heavy snorers can suffer obstructive apnoea and alveolar hypoventilation during sleep as well as an increase in pulmonary and systemic arterial pressures. $^{70}$

Bloom and coworkers have found that cigarette smoking, obesity, male gender, and age are risk factors for snoring and that snoring is associated with cough and sputum production. ${ }^{10}$ Snoring is common in adults $\left(24-71 \%\right.$ of men and $14-52 \%$ of women $\left.^{4}\right)$, and the prevalence tends to increase with age.'

Snoring during childhood has been investigated only in selected clinical samples, and it has been found to be associated with sleep apnoea and related symptoms such as excessive daytime somnolence, hyperactivity, and behavioural or intellectual changes. ${ }^{11 \cdot 13}$ These observations suggested that chronic snoring in a child should prompt appropriate investigation and treatment. ${ }^{14}$ Despite evidence of the clinical consequences of snoring no data are available regarding the prevalence of snoring in a general population of children.

We investigated the prevalence of snoring in a general population sample of children aged 6-13 years and the occurrence of snoring in association with age, sex, respiratory symptoms, and parental passive smoking.

\section{Methods}

The study was conducted in two towns in the Abruzzo region (Guardiagrele and Francavilla) in central Italy. We studied the overall population of schoolchildren in the first degree (aged 6-11 years) (1907 subjects: 964 boys and 943 girls) and in the second degree (aged 10-13 years) (455 subjects: 235 boys and 220 girls). The rate of compliance was $97 \%$. To avoid possible bias towards non-snorers we excluded from the analysis children who had been sleeping alone because the prevalence of snoring in these children was significantly lower than in children sharing a bedroom with siblings or parents $(3.6 \% v$ $\left.7 \cdot 3 \% ; \chi^{2}=10 \cdot 7 ; p=0.0011\right)$. The excluded sample $(747$ subjects: 389 boys and 358 girls) did not differ as regards age, sex, respiratory symptoms, and smoking habits of the parents from the examined group ( 1615 subjects: 810 boys and 805 girls, aged 6-13 years). Data on snoring, respiratory symptoms, and parental smoking were obtained from a modified American Thoracic Society children's questionnaire, ${ }^{15}$ which was completed by the parents.

\section{DEFINITIONS}

The question concerning snoring was: "Does your child ever snore?" On the basis of the answer four categories were formed: (1) never; (2) only with colds; (3) occasionally apart from with colds; and (4) often. Children included in the last category were defined as habitual snorers.

Asthma was defined as an affirmative response to a question about whether the child had been told that he or she had asthma by a doctor. Rhinitis was defined in terms of response to the following question: "Has your child ever had rhinitis (stuffy and running nose, itchy eyes, sneezing)?" Cough and phlegm were defined as cough or phlegm that occurred apart from with colds. 